\title{
Assessment of angiogenesis by CD105 and nestin expression in peritumor tissue of glioblastoma
}

\author{
GIGLIOLA SICA $^{1 *}$, GINA LAMA $^{1 *}$, CARMELO ANILE $^{2}$, MARIA CONCETTA GELOSO $^{3}$, \\ GIUSEPPE LA TORRE ${ }^{5}$, PASQUALE DE BONIS ${ }^{2}$, GIULIO MAIRA ${ }^{2}$, LIBERO LAURIOLA ${ }^{4}$, \\ MEENA JHANWAR-UNIYAL ${ }^{6}$ and ANNUNZIATO MANGIOLA ${ }^{2}$
}

\author{
${ }^{1}$ Institute of Histology and Embryology, ${ }^{2}$ Institute of Neurosurgery, ${ }^{3}$ Institute of Anatomy and Cell Biology, \\ ${ }^{4}$ Institute of Pathology, Faculty of Medicine, Catholic University of the Sacred Heart, Largo Francesco Vito 1, I-00168 Rome; \\ ${ }^{5}$ Department of Experimental Medicine, Sapienza University of Rome, Viale Regina Elena 324, I-00161 Rome, Italy; \\ ${ }^{6}$ Departments of Neurosurgery and Experimental Pathology, New York Medical College, Valhalla, NY 10595, USA
}

Received August 4, 2010; Accepted October 1, 2010

DOI: 10.3892/ijo_00000822

\begin{abstract}
Angiogenesis in the peritumor tissue of glioblastoma (GBM) is still an open field of research. This study investigates neovascularization in the tumor surrounding areas by examining CD105 and nestin expression along with microvessel density (MVD) with the aim of establishing their possible prognostic significance. Angiogenesis was also confirmed by investigating, in vessel walls, the presence of pericytes, which are multipotent stem cells, expressing $\alpha$-smooth muscle actin ( $\alpha$-SMA). In our study, including 40 GBM patients, tissue samples were obtained from tumors (first area) and white matter at a distance $<1 \mathrm{~cm}$ (second area) and between 1 and $3.5 \mathrm{~cm}$ (third area) from the tumor margin. CD105 and nestin were detected by immunohistochemistry in hyperplastic endothelium of GBM and peritumor tissue, and occasionally coexpressed or colocalized. Pericytes encircling hyperplastic endothelium were evident in all three areas. Univariate analysis revealed that patients with a CD105MVD value $\geq 8$ in the third area have a significantly shorter survival time and Cox analysis indicated an about 3.5-fold increase in death risk in the same patients. These results demonstrate that a tumor neoangiogenesis occurs in GBM peritumor tissue with intimate involvement of pericytes. CD105-MVD in the area located at a greater distance from the tumor margin carries prognostic significance.
\end{abstract}

Correspondence to: Professor Gigliola Sica, Institute of Histology and Embryology, Faculty of Medicine, Catholic University of the Sacred Heart, Largo Francesco Vito 1, I-00168 Rome, Italy

E-mail gigliola@rm.unicatt.it

${ }^{*}$ Contributed equally

Key words: glioblastoma, peritumor tissue, angiogenesis, CD105, nestin, microvessel density

\section{Introduction}

Tumor growth and metastasis require adequate vascularization. Glioblastoma (GBM) is among the most vascularized tumors. Different mechanisms have been proposed in determining the vasculature characteristics (1). Specifically, a model of tumor progression defining the relationship between angiogenesis and the development of pseudopalisading necrosis, which represents a peculiar histopathological feature of GBM, has been suggested (2). According to this model, vascular occlusion, provoked by infiltrating tumor cells, induces hypoxia with a central necrosis surrounded by neoplastic elements which, in turn, produce hypoxia-inducible factors responsible for exuberant angiogenesis. In regions adjacent to hypoxia, this response creates microvascular proliferation (2), that typically appears as glomeruloid tufts (1). Microvessel morphology also depends on tumor size and in larger neoplasias appears chaotic (3), with angiogenic activity that is very high next to the tumor margin and decreases towards the center of the tumor $(4,5)$. Vascular glomeruli have also been observed in the white matter surrounding the tumor but less frequently in the cortex. The number, caliber and wall thickness mean values of vessels in peritumor white matter are significantly higher than those of the normal brain (6). The area adjacent to the tumor margin, where the angiogenic response has been observed, represents the invasion front into the neighboring tissue. In this area, differences in the level of various molecules involved in enhanced cell proliferation, edema and invasiveness have been observed (7-11).

These findings suggest that the peritumor compartment undergoes significant modifications in terms of vascularization and biomolecular features. Nevertheless, all the above reports do not define the areas of peritumor tissue used for analysis, nor their distance from the tumor edge. In this regard, we recently showed in peritumor tissue, up to $3.5 \mathrm{~cm}$ from the tumor margin, the presence of phosphorylated (p) extracellular signal-regulated kinases (ERKs) and c-Jun $\mathrm{NH}_{2}$ terminal kinases $(\mathrm{JNKs})(12,13)$ regulating cell proliferation, differentiation, motility and apoptosis (14). The neural stem cell 
marker nestin was also expressed in the same tissue. Both kinases and nestin were present not only in activated astrocytes but also in apparently normal glial cells. In addition, the $\mathrm{pJNK} /$ nestin and $(\mathrm{pJNK} /$ total JNK)/nestin ratios at a distance $<1 \mathrm{~cm}$ from the tumor border have been shown to carry a prognostic significance in GBM patients (13).

Markers of endothelial activation, such as pERK1/2, pJNKs and nestin, are expressed in the vessel walls of both GBM and peritumor areas $(12,13,15,16)$ and their expression may be induced by growth factors and chemokines secreted by tumor cells, which diffuse in the peritumor areas and are presumably involved in the rapid turnover of the endothelial cells.

To test the hypothesis that the angiogenesis occurring in peritumor areas is devoted to tumor progression, we investigated it in the peritumor brain tissue by analyzing the expression of nestin and CD105.

CD105 is a $180-\mathrm{kDa}$ integral membrane glycoprotein, which is an accessory component of the receptor complex of transforming growth factor-beta (TGF-B) (17). CD105 expression has been successfully used to investigate tumor angiogenesis in various neoplasias, including GBM, non-small cell lung and prostate cancer. CD105 appears to be able to distinguish between normal vessels and malignant neovascularization (18-21).

In our study, microvessel density (MVD) was also evaluated both in GBM and peritumor tissue and correlated with prognosis. Finally, a further characterization of vascular morphology was performed by immunohistochemical detection of $\alpha$-smooth muscle actin ( $\alpha$-SMA), a specific marker of pericytes. These cells have recently been demonstrated to possess stem cell properties $(22,23)$.

\section{Patients and methods}

Patients and tissue samples. This study involved 40 adult patients with primary supratentorial GBM who underwent surgery at the Institute of Neurosurgery of the Catholic University in Rome. Based on the patients' clinical history, the GBMs were considered as primary. In fact, the time-interval between first symptom-signs of disease and admission to hospital was very short in all cases and patients had a rapid clinical progression of disease. Neuronavigation and intraoperative ultrasound were used to define and maximize the extent of intracranial tumor resection. Tumor and neighboring apparently normal tissue were removed en bloc. The surgical specimens were cut and opened in a book-wise fashion. By this technique, the difference between tumor border and its surrounding apparently normal white matter was evident (24), which made easy the definition of the distance from tumor border to peripheral white matter where the samples could be taken. Early contrast MRI (within 24/48 h after surgery) confirmed both the complete removal of the enhanced lesion (no residual contrast enhancement) and the extent of resection over it.

Tissue samples were obtained from the area of the tumor without hemorrhage and necrosis (first area), white matter at a distance $<1 \mathrm{~cm}$ (second area) and between 1 and $3.5 \mathrm{~cm}$ (third area) from the macroscopic tumor border. The larger resections were done in tumors growing far from eloquent areas. Nevertheless, neoplasm anatomic location did not always allow us to obtain samples from the three areas; 40 tissue specimens were derived from the first, 34 from the second and 29 from the third area. Thirty-five days after surgery (range 30-40 days), all patients underwent irradiation and chemotherapy performed according to literature (25). Informed consent to use tumor and peritumor material as well as clinical data for research purposes was received from all patients.

Histological analysis. All samples were fixed in 10\% formalin immediately after excision and processed for paraffin sections. Specimens were histologically assessed using H\&E sections by an expert pathologist (Libero Lauriola). Neoplastic cells were identified by their nuclear atypia and heteropycnotic staining. Reactive astrocytes were recognized by dendritic morphology of their abundant eosinophilic cytoplasm and large eccentric nuclei (26). Tumors were classified according to the World Health Organization (WHO) criteria (27).

Immunohistochemistry. Paraffin-embedded tissue sections (5- $\mu \mathrm{m}$ thick), from tumor and peritumor samples, were deparaffinized and rehydrated, and the antigens were retrieved by pronase digestion (ProTaqs ${ }^{\circledR}$ Pronase Digest, Germany), for CD105 detection, and by microwaving in sodium citrate buffer ( $\mathrm{pH}$ 6.0) for nestin, while no antigen retrieval was required for $\alpha$-SMA. After blocking, sections were incubated with the following mouse monoclonal antibodies: anti-CD105 (clone SN6h; 1:10; DakoCytomation Inc., Carpinteria, CA, USA) for $2 \mathrm{~h}$ at room temperature (RT), or anti-nestin (clone 10C2; 1:200; Chemicon International, CA, USA) overnight at $4^{\circ} \mathrm{C}$ or with anti- $\alpha$-SMA (clone HHF35; 1:100; DakoCytomation Inc.) for $1 \mathrm{~h}$ at RT. Subsequently, slides were incubated with HRP polymer (SuperPicTure Polymer Detection Kit, Invitrogen, Camarillo, CA, USA). The immunoreaction was visualized with DAB (Vector Laboratories, Inc., Burlingame, CA, USA) as the chromogen. The nuclei were lightly counterstained with Mayer's hematoxylin. Negative controls were set up by omitting the primary antibodies.

Quantification of angiogenesis. MVD of the tumor and peritumor tissue was assessed by light microscopic analysis (Axioskop 2 Plus, Zeiss, Göttingen, Germany). Areas of highest neovascularization (hot spots) composed of capillaries and small venules (microvessels) were identified by scanning the sections at low power (x100) and selecting those areas with the greatest numbers of CD105- or nestin-positive microvessels. Individual microvessel counts were then made on a x200 field $\left(0.78 \mathrm{~mm}^{2}\right.$ per field with the field size measured with an ocular micrometer).

Single endothelial cell and larger vessels, independently of the calibre, were considered in the counts $(28,29)$. Five hot spot fields were counted and the average was regarded as the MVD of that section (30). CD105-MVD was evaluated in both tumor and peritumor tissue. It was not feasible to determine nestin-MVD in the first area due to the high nestin expression in the majority of neoplastic cells of GBM. For this reason, it was evaluated in the peritumor areas only. All counts were performed by two investigators. 
Table I. Clinicopathological characteristics of the 40 adult patients with primary GBM.

\begin{tabular}{|c|c|c|c|c|c|c|c|}
\hline Patients & Gender & $\begin{array}{c}\text { Age at } \\
\text { diagnosis } \\
\text { (years) }\end{array}$ & $\begin{array}{c}\text { Tumor } \\
\text { localization }\end{array}$ & $\begin{array}{l}\text { KPS } \\
\text { score }\end{array}$ & Treatment & $\begin{array}{l}\text { Survival time } \\
\quad \text { (months) }\end{array}$ & $\begin{array}{l}\text { Clinical } \\
\text { outcome }\end{array}$ \\
\hline 1 & M & 67 & Parieto-temporal & 80 & $\mathrm{RT}+\mathrm{CH}$ & 8 & DOD \\
\hline 2 & M & 63 & Frontal & 100 & $\mathrm{RT}+\mathrm{CH}$ & 11 & DOD \\
\hline 3 & $\mathrm{~F}$ & 47 & Frontal & 100 & $\mathrm{RT}+\mathrm{CH}$ & 14 & DOOC \\
\hline 4 & $\mathrm{~F}$ & 65 & Parieto-occipital & 80 & $\mathrm{RT}+\mathrm{CH}$ & 18 & DOD \\
\hline 5 & $\mathrm{~F}$ & 58 & Frontal & 100 & $\mathrm{RT}+\mathrm{CH}$ & 15 & DOD \\
\hline 6 & $\mathrm{~F}$ & 71 & Frontal & 80 & $\mathrm{RT}+\mathrm{CH}$ & 13 & DOD \\
\hline 7 & $\mathrm{~F}$ & 61 & Frontal & 100 & $\mathrm{RT}+\mathrm{CH}$ & 12 & DOD \\
\hline 8 & M & 58 & Parieto-temporal & 80 & $\mathrm{RT}+\mathrm{CH}$ & 19 & DOD \\
\hline 9 & M & 72 & Parietal & 90 & $\mathrm{RT}+\mathrm{CH}$ & 12 & DOD \\
\hline 10 & M & 43 & Parietal & 80 & $\mathrm{RT}+\mathrm{CH}$ & 19 & DOD \\
\hline 11 & $\mathrm{~F}$ & 62 & Temporal & 80 & $\mathrm{RT}+\mathrm{CH}$ & 17 & DOD \\
\hline 12 & $\mathrm{~F}$ & 68 & Frontal & 90 & $\mathrm{RT}+\mathrm{CH}$ & 28 & DOD \\
\hline 13 & $\mathrm{~F}$ & 49 & Frontal & 100 & $\mathrm{RT}+\mathrm{CH}$ & 59 & DOD \\
\hline 14 & $\mathrm{~F}$ & 47 & Frontal & 100 & $\mathrm{RT}+\mathrm{CH}$ & 25 & DOD \\
\hline 15 & $\mathrm{~F}$ & 65 & Frontal & 90 & - & 2 & DOOC \\
\hline 16 & M & 69 & Frontal & 70 & - & 0.1 & DOOC \\
\hline 17 & M & 57 & Fronto-parietal & 100 & $\mathrm{RT}+\mathrm{CH}$ & 18 & DOD \\
\hline 18 & M & 71 & Parietal & 80 & $\mathrm{RT}+\mathrm{CH}$ & 22 & DOD \\
\hline 19 & M & 68 & Temporal & 100 & $\mathrm{RT}+\mathrm{CH}$ & 12 & DOD \\
\hline 20 & M & 61 & Fronto-temporal & 100 & $\mathrm{RT}+\mathrm{CH}$ & 13 & DOD \\
\hline 21 & $\mathrm{~F}$ & 72 & Parieto-temporal & 90 & $\mathrm{RT}+\mathrm{CH}$ & 15 & DOD \\
\hline 22 & $\mathrm{~F}$ & 62 & Fronto-parietal & 80 & $\mathrm{RT}+\mathrm{CH}$ & 14 & DOD \\
\hline 23 & M & 44 & Frontal & 100 & $\mathrm{RT}+\mathrm{CH}$ & 19 & DOD \\
\hline 24 & $\mathrm{~F}$ & 72 & Frontal & 80 & - & 0.2 & DOOC \\
\hline 25 & $\mathrm{~F}$ & 72 & Frontal & 80 & $\mathrm{RT}+\mathrm{CH}$ & 6 & DOD \\
\hline 26 & M & 68 & Temporal & 80 & - & 3 & DOOC \\
\hline 27 & M & 51 & Temporal & 100 & $\mathrm{RT}+\mathrm{CH}$ & 9 & DOD \\
\hline 28 & M & 42 & Temporal & 100 & $\mathrm{RT}+\mathrm{CH}$ & 36 & Alive \\
\hline 29 & M & 52 & Parieto-temporal & 80 & $\mathrm{RT}+\mathrm{CH}$ & 13 & DOD \\
\hline 30 & $\mathrm{~F}$ & 49 & Parieto-occipital & 90 & $\mathrm{RT}+\mathrm{CH}$ & 8 & DOD \\
\hline 31 & $\mathrm{~F}$ & 52 & Temporal & 90 & $\mathrm{RT}+\mathrm{CH}$ & 30 & Alive \\
\hline 32 & M & 20 & Parieto-occipital & 100 & $\mathrm{RT}+\mathrm{CH}$ & 28 & DOD \\
\hline 33 & M & 71 & Fronto-temporal & 90 & $\mathrm{RT}+\mathrm{CH}$ & 5 & DOD \\
\hline 34 & M & 75 & Parietal & 80 & $\mathrm{RT}+\mathrm{CH}$ & 6 & DOD \\
\hline 35 & $\mathrm{~F}$ & 59 & Temporal & 100 & $\mathrm{RT}+\mathrm{CH}$ & 10 & DOD \\
\hline 36 & $\mathrm{~F}$ & 71 & Frontal & 80 & $\mathrm{RT}+\mathrm{CH}$ & 9 & DOD \\
\hline 37 & $\mathrm{~F}$ & 75 & Parietal & 80 & - & 1 & DOOC \\
\hline 38 & $\mathrm{~F}$ & 43 & Parieto-occipital & 100 & $\mathrm{RT}+\mathrm{CH}$ & 18 & Alive \\
\hline 39 & M & 51 & Parieto-temporal & 90 & $\mathrm{RT}+\mathrm{CH}$ & 12 & Alive \\
\hline 40 & M & 69 & Temporal & 100 & $\mathrm{RT}+\mathrm{CH}$ & 12 & Alive \\
\hline
\end{tabular}

M, male; F, female; KPS, Karnofsky performance status; RT, radiotherapy; CH, chemotherapy; DOD, dead of disease; DOOC, dead of other causes.

Confocal microscopy. Cryostat sections of two tumor and To determine co-expression of CD105 and nestin, double peritumor tissue samples were fixed in formaldehyde $1 \%$. staining procedure was achieved using the antibodies described 
above. After blocking, tissue sections were incubated with anti-nestin antibody for $72 \mathrm{~h}$ at $4^{\circ} \mathrm{C}$. They were then incubated with secondary antibody conjugated with red fluorescent cyanine (donkey anti-mouse Cy3; 1:200; Jackson Immunoresearch Laboratories, West Grove, PA, USA) for $2 \mathrm{~h}$ at RT. Before the incubation with anti-CD105 antibody, an additional blocking step was performed with goat antimouse FAB-fragments (1:1000; Dianova, Hamburg, Germany) for $1 \mathrm{~h}$ at RT. Subsequently, slides were incubated with the secondary antibody (donkey anti-mouse Cy2; 1:200; Jackson Immunoresearch Laboratories) conjugated with green fluorochrome. Primary antibodies were omitted for negative controls. The colocalization of markers was examined with Zeiss LSM 510 confocal laser scanning microscopy system.

Statistical analysis. The statistical analyses were carried out using SPSS software version 15.1. The following nonparametric tests were applied to find statistically significant differences among groups: Kruskal-Wallis test to compare the CD105-MVD among the three areas; Mann-Whitney (unpaired data) and Wilcoxon signed rank (paired data) tests, in order to find differences in CD105-MVD between two areas. The latter two tests were also utilized to compare the nestin-MVD in the peritumor areas. Spearman's correlation was used to assess the relationship between CD105-MVD and nestin-MVD in the peritumor areas.

Patients' survival rates were determined by the KaplanMeier method. Survival time was computed from the date of surgery to the date of death or the last follow-up for patients still alive. The correlation between age ( $<60$ and $\geq 60$ years), KPS (KPS $=80$ and KPS=90-100), extent of resection of T2 abnormality $(<1 \mathrm{~cm}$ and $\geq 1 \mathrm{~cm})$, gender, biological variables, and survival was analyzed using the log-rank and Breslow tests. Patients were dichotomized into two groups, based on the median value of each biological variable as the cut-off point. For those factors showing an association with survival at univariate analysis, a multivariate analysis was conducted (Cox proportional hazards model). Stepwise (backward elimination) procedure was used. For all tests, the level of statistical significance was set at $\mathrm{p}<0.05$.

\section{Results}

The clinicopathological characteristics of the patients are reported in Table I. Patient (20 females and 20 males) age ranged from 20 to 75 years (mean 59.8 years) and median KPS was 90 (range 70-100). At the time of the survival analysis, of the 40 patients 5 were still alive, 29 had died of cancer and 6 had died of other causes.

Expression of CD105, nestin and $\alpha-S M A$ in tumor and peritumor areas. In the tumor area, typical features of marked hypercellularity, nuclear atypia, frequent mitoses, and vascular proliferation were observed (Fig. 1A). The majority of GBM vascular formations were represented by hyperplastic microvessels as solid-glomeruloid, channeled-branching and channeled-telangiectatic vessels, in agreement with literature (31). Peritumor areas were characterized by a decrease in cell density. Neoplastic appearing cells were present in various percentages (Fig. 1D and G) or absent (Fig. 1J), apart from apparently normal glial cells and reactive hypertrophic astro- cytes. Furthermore, vascularization in the peritumor tissue resembled that seen in GBM.

CD105 immunoreactivity was detected in both tumor (Figs. $1 \mathrm{~B}$ and 2A) and peritumor tissue (Figs. 1E, $\mathrm{H}$ and $\mathrm{K}$ and $2 \mathrm{~B}, \mathrm{C}$ and $\mathrm{D}$ ). The expression was revealed by an intense cytoplasmic staining and was restricted to endothelial cells of vessels of different size. In peritumor areas, CD105 immunostaining was present in microvessels of small size and in hyperplastic microvessels, which resembled those found in the tumor. These microvessels appeared like solid-glomeruloid vessels (Fig. 1E), channeled-branching vessels (Fig. 1H), and channeled-telangiectatic vessels (Fig. 1E, H, and K). Labeled cells were hypertrophic showing large, plump, elongated or ovoid nuclei that clumped up inside of vascular lumina (Fig. 2A-D), as described in the literature (32). Importantly, immunoassaying was independent of the presence of infiltrating tumor cells (Figs. 1K and 2D).

As previously reported by our group (13), cytoplasm nestin immunoreactivity was detected in the majority of neoplastic cells of the first area (Fig. 1C) and in few cells of the second and third areas (Fig. 1F, I and L), including neoplastic elements, reactive glial cells and apparently normal cells (Fig. 2E-G). Nestin decorated endothelial cells of both microvessels and hyperplastic microvessels (Fig. 1F, I and L). Hypertrophy of endothelial cells, analogously to that visualized by CD105 expression, is shown in Fig. 2E-G. The immunoreactivity of nestin was observed both in the presence (Figs. 1F, and I, 2E and F) and in the absence (Figs. 1L and 2G) of neoplastic cells.

Confocal microscopy analysis of double-labeled samples revealed CD105 and nestin co-expression in some vessels present in the three areas examined. In particular, in the tumor area endothelial cells expressed CD105 mainly visible near the vascular lumen (Fig. 3C and F), while in the peritumor tissue (third area), CD105 and nestin immunoreactivity overlapped (Fig. 3I).

Finally, the vessel walls revealed the presence of pericytes with intense cytoplasmic staining for $\alpha$-SMA. Also, these cells encircled endothelium with their projections and sometimes seemed to clump up inside vascular lumina (Fig. 2 H-J).

MVD in GBM and peritumor tissue. CD105-MVD was higher in the first area compared with the second and the third ones (Table IIA). The Kruskal-Wallis test demonstrated a difference in CD105-MVD among the three areas $(p<0.001)$. Similarly, the Mann-Whitney and Wilcoxon signed rank tests revealed a difference between the first and the second areas $(\mathrm{p}<0.001)$ and between the first and the third areas $(\mathrm{p}<0.001)$. These results indicated that the differences are present not only between the areas considered together, but also in the different areas of the same subject. Both the latter tests showed no differences between the second and the third areas $(p=0.091$ and 0.052 , respectively). The Mann-Whitney test did not reveal any difference in CD105-MVD in the two peritumor areas in relation to the presence or absence of tumor cells ( $\mathrm{p}=0.259$ and 0.104 , respectively; Table IIB). Nestin-MVD showed no differences between the second and the third areas ( $\mathrm{p}=0.369$ and 0.424, Wilcoxon signed rank and Mann-Whitney tests, respectively) (Table IIA). The Mann-Whitney test did not reveal any difference in nestin-MVD in the two peritumor 
$\mathrm{H} \& \mathrm{E}$
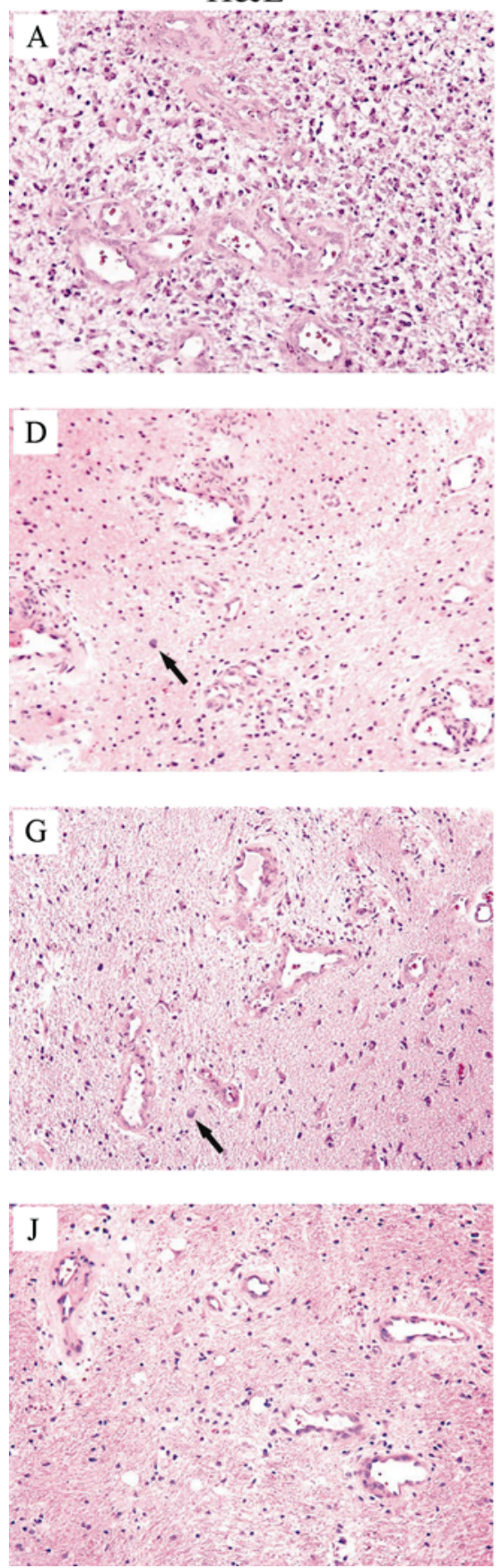

CD105

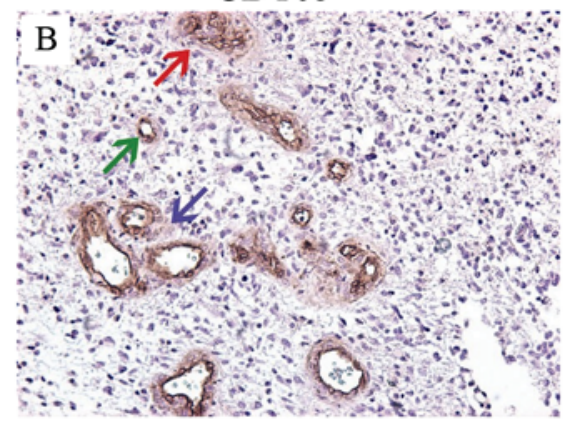

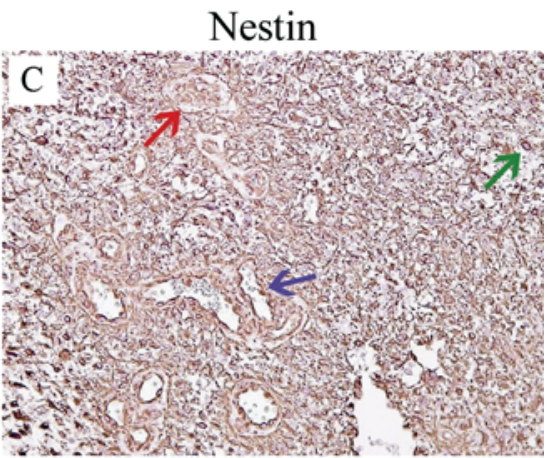
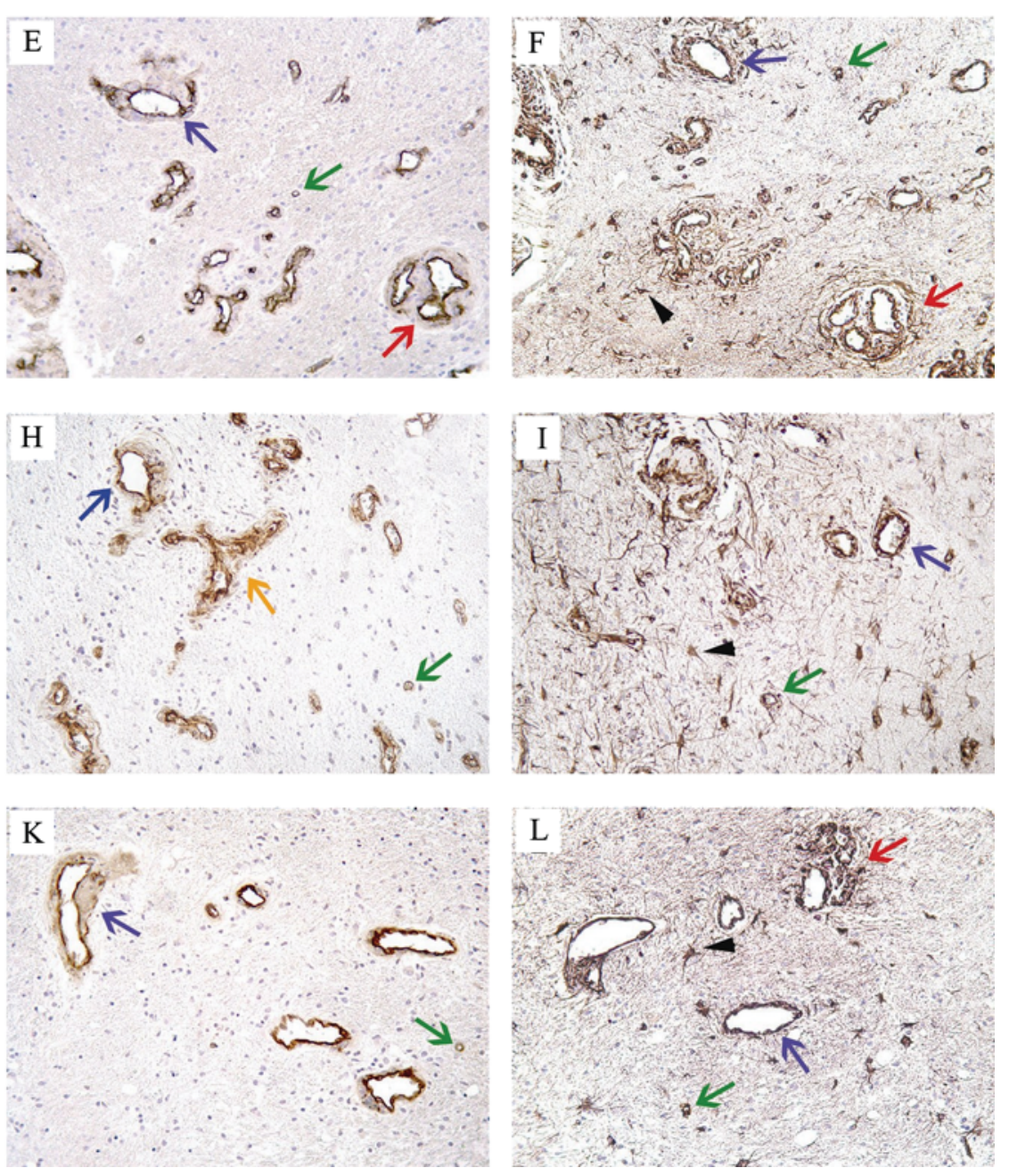

Figure 1. Location of CD105 and nestin in microvessels of GBM and peritumor tissue. Sections from: first area (A-C), second (D-F) and third areas (G-I) with neoplastic appearing cells, third area (J-L) without neoplastic appearing cells. H\&E staining in first area (A), in second (D) and third area (G) with scant cells exhibiting moderately atypical nuclei suspected for neoplasia (black arrow), in third area (J) without neoplastic cells. CD105 immunoreactivity was observed in various hyperplastic vessels of the first (B), second (E), and third area with (H) or without (K) neoplastic cells. Nestin was detected in neoplastic cells and in endothelium of different types of hyperplastic vessels in the first area (C). In the second (F) and third area with (I) or without (L) neoplastic cells, nestin labeled endothelial cells of microvessels and reactive astrocytes (black head arrow). Red arrows, solid glomeruloid vessels; blue arrows, channelledtelangiectatic vessels; orange arrows, channelled-branching vessels; green arrows, small microvessels. Original magnification, x200 (A-L). Hematoxylin counterstain.

areas in relation to the presence or absence of tumor cells ( $\mathrm{p}=0.849$ and 0.228 , respectively; Table IIB). Nestin-MVD was higher than CD105-MVD only in the third area $(p=0.031$, Wilcoxon signed rank test).

A positive correlation was observed between CD105-MVD of the second and that of the third areas $(p=0.003$, Rho $=0.583$, Spearman's correlation), and between nestin-MVD of the two peritumor areas $(\mathrm{p}=0.031$, $\mathrm{Rho}=0.449$, Spearman's correlation).
No correlation was observed between CD105-MVD and nestin-MVD in the two peritumor areas $(p=0.060$ in the second area; $\mathrm{p}=0.434$, in the third area, Spearman's correlation).

Survival analysis. The Kaplan-Meier analysis was performed on 35 patients, because patients who did not receive radiochemotherapy were excluded (Table I). The analysis indicated that KPS, extent of resection and gender were not associated 


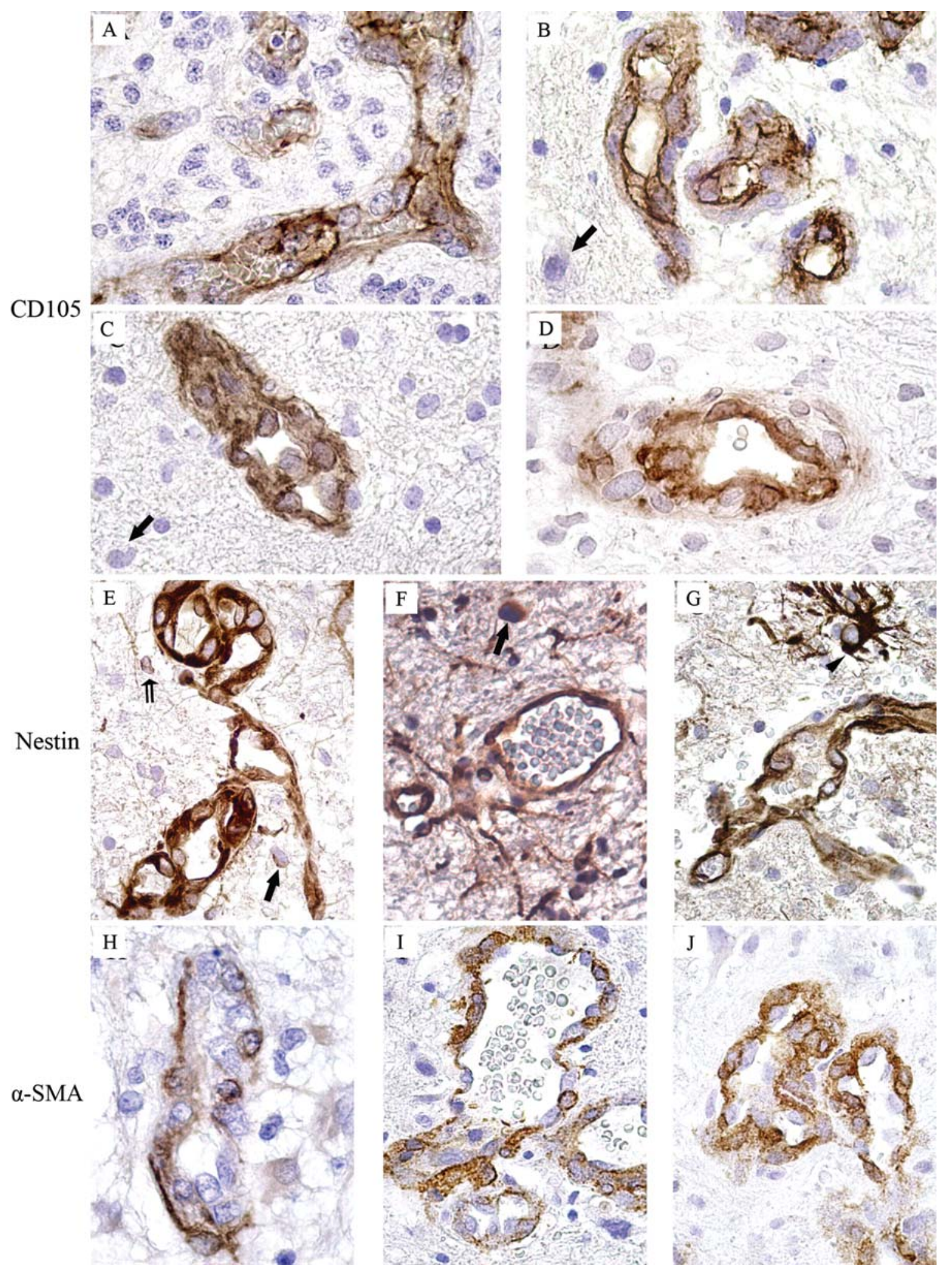

Figure 2. Features of CD105, nestin and $\alpha$-SMA expression in GBM and peritumor areas. In the first area (A), tumor microvessels showed intense cytoplasmic CD105 staining in endothelial cells; CD105 was not detected in tumor cells. In the second (B) and third (C) areas, CD105 was strongly expressed in the cytoplasm of hypertrophic endothelium, which showed nuclei with a large and ovoidal morphology, but not in neoplastic appearing cells (black arrow). In the third area without neoplastic cells (D), CD105 strongly expressed is present only in endothelium. In the second (E) and third area (F) with neoplastic cells, nestin was seen in hyperplastic microvessel endothelium, in tumor cells (black arrow), and in apparently normal cells (open arrow). In the third area without neoplastic cells $(\mathrm{G})$, nestin was evident in endothelium and in the reactive astrocytes with cytoplasm extensions (black head arrow). Intense cytoplasmic staining for $\alpha$-SMA of pericytes was seen in the first $(\mathrm{H})$, second (I) and third (J) area. Original magnification x630 (A-J). Hematoxylin counterstain.

with survival. Significant associations were found between survival and age-group ( $\geq 60$ vs $<60$ years), and between survival and CD105-MVD in the third area. In fact, the median survival was better for patients with age $<60$ (19 vs 12 months; 


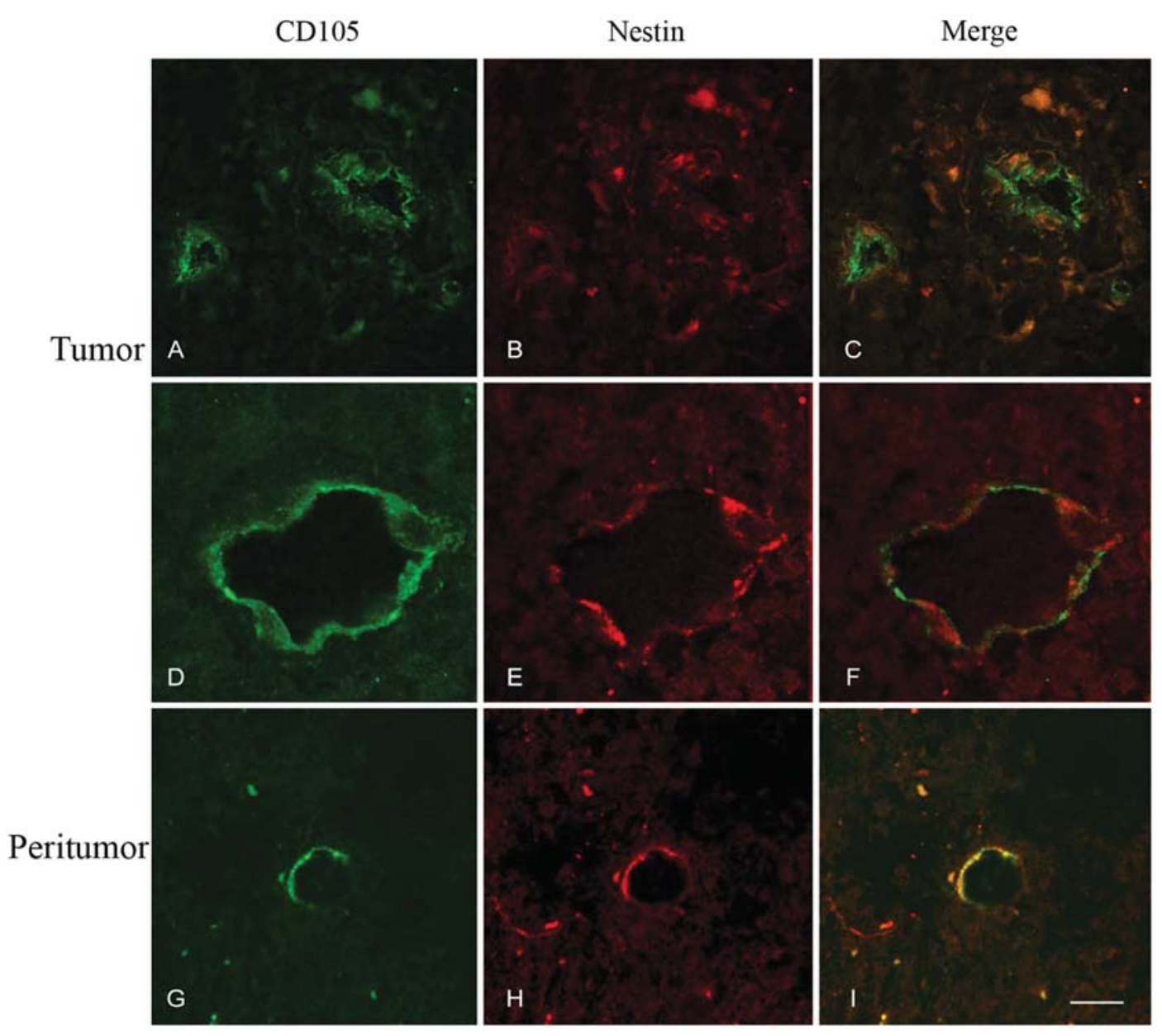

Figure 3. Confocal microscopy images of CD105 (green) and nestin (red) expression in tumor (A-F) and peritumor (G-I) microvessels. The merged images show that in the first area the two markers seemed to be localized in different regions of the same endothelial cells $(\mathrm{C}$ and $\mathrm{F})$, while in peritumor areas they essentially overlapped (I). Scale bar, $15 \mu \mathrm{m}$ (A-C); $5 \mu \mathrm{m}$ (D-F); $10 \mu \mathrm{m}$ (G-I).

Table II. A, CD105-MVD in the first area and peritumor areas, nestin-MVD in peritumor areas.

\begin{tabular}{lccc}
\hline & 1st area & 2nd area & 3rd area \\
\hline No. of samples & 40 & 34 & 29 \\
CD105-MVD & & & \\
$\quad$ Median (range) & $30.70(9.0-151.40)$ & $12.30^{\mathrm{a}}(1.80-23.80)$ & $8.0^{\mathrm{a}} \quad(1.60-22.0)$ \\
Nestin-MVD & & & \\
Median (range) & & $10.70(4.60-45.60)$ & $12.60(3.80-39.40)$ \\
\hline
\end{tabular}

B, CD105- and nestin-MVD in peritumor areas in relation to neoplastic cells.

\begin{tabular}{lcccc}
\hline & $\begin{array}{c}\text { 2nd area with } \\
\text { tumor cells }\end{array}$ & $\begin{array}{c}\text { 2nd area without } \\
\text { tumor cells }\end{array}$ & $\begin{array}{c}\text { 3rd area with } \\
\text { tumor cells }\end{array}$ & $\begin{array}{c}\text { 3rd area without } \\
\text { tumor cells }\end{array}$ \\
\hline No. of samples & 14 & 20 & 10 & 19 \\
$\begin{array}{c}\text { CD105-MVD } \\
\text { Median (range) }\end{array}$ & $13.30(3.40-23.80)$ & $10.30(1.80-23.0)$ & $10.90(3.80-22.0)$ & $5.80(1.60-18.80)$ \\
$\begin{array}{c}\text { Nestin-MVD } \\
\text { Median (range) }\end{array}$ & $11.0(4.60-41.60)$ & $10.20(5.80-45.60)$ & $10.20(3.80-15.20)$ & $13.20(6.0-39.40)$ \\
\hline
\end{tabular}

MVD, microvessel density; ${ }^{\mathrm{a}} \mathrm{p}<0.001$ vs. 1 st area, Wilcoxon and Mann-Whitney tests. 

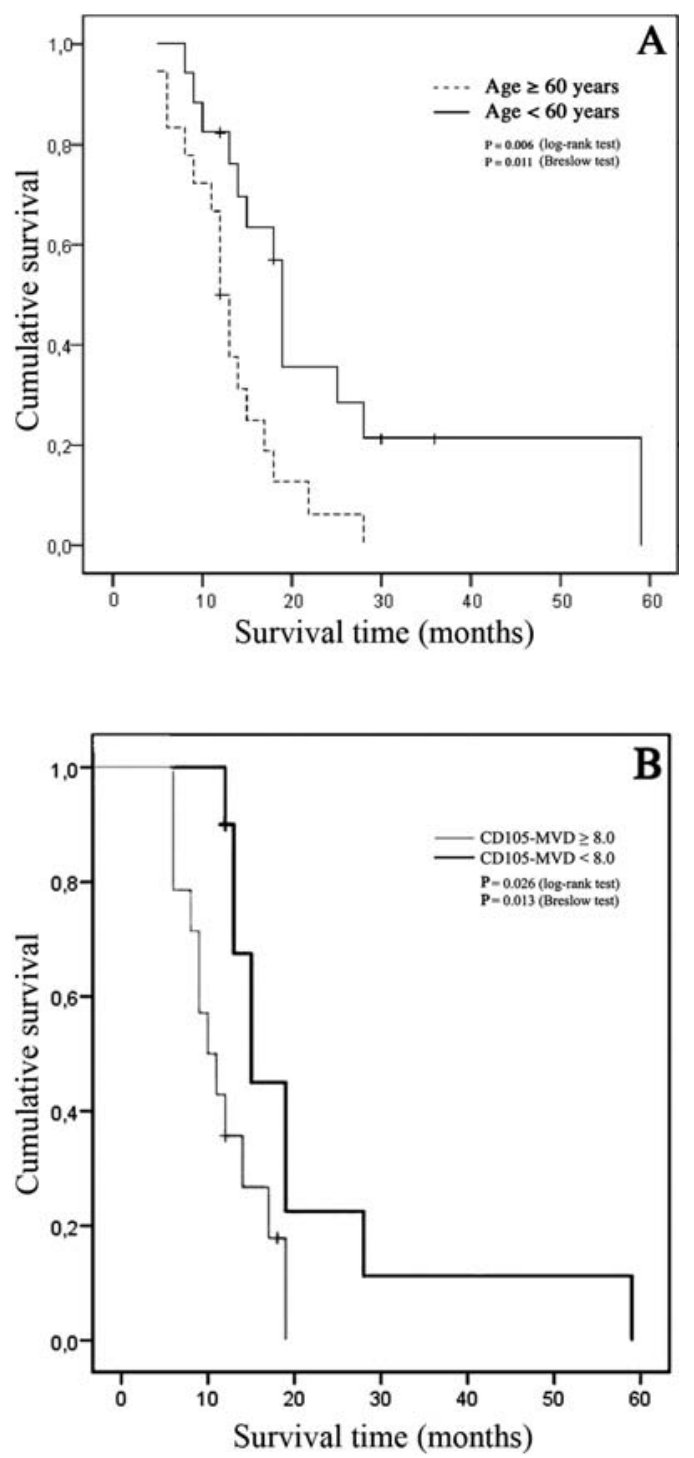

Figure 4. The Kaplan-Meier plots depict the differences in survival when patients were dichotomized into two age groups ( $\geq 60 \mathrm{vs}<60$ years) or by the median value of CD105-MVD in the third area. The median survival was better for patients $<60$ years of age (19 vs 12 months) (A), and for those patients with CD105-MVD $<8.0$ compared to patients with CD105-MVD values $\geq 8.0$ (15 vs 10 months) (B).

$\mathrm{p}=0.006$ log-rank test; $\mathrm{p}=0.011$, Breslow test) (Fig. 4A). The median survival was also better for patients with CD105MVD values <8.0 compared to patients with CD105-MVD values $\geq 8.0$ ( 15 vs 10 months; $p=0.026$ log-rank test; $p=0.013$, Breslow test) (Fig. 4B).

Moreover, CD105-MVD values $\geq 8.0$ in the third area were independently associated with survival after the adjustment for age-group, sex and KPS included in the Cox model (HR of $3.37 ; 95 \% \mathrm{CI}=1.24-9.10 ; \mathrm{p}=0.017)$. Age was also found to be independently associated with survival ( $\geq 60$ vs $<60$ years: $\mathrm{HR}=3.32 ; 95 \% \mathrm{CI}$ : $1.24-8.87 ; \mathrm{p}=0.016)$.

\section{Discussion}

The results of this study indicate that peritumor tissue located not only immediately around the tumor margin, as reported in literature, but also at a considerable distance, harbors a florid microvascular proliferation. This microvasculature carries the same characteristics as those seen in GBM and is independent of the presence of morphologically detectable neoplastic cells.

Microvessels and hyperplastic microvessels, which are composed of hypertrophic endothelial cells that protrude into the lumina causing their restriction, are present. Pericyte-like cells, showing a strong positivity for $\alpha$-SMA, surround the endothelium. They may stabilize new formed microvessels, be pioneers in the sprouting process or replicate under the stimulus of growth factors and differentiate into endothelial cells, smooth muscle cells as well as cells displaying the antigenic properties of astrocytes, neurons, and oligodendrocytes $(22,33,34)$. Endothelial cells express both nestin and CD105 which show different localization in tumor vessels compared with vessels of the tissue surrounding GBM, which warrants further investigation.

In peritumor areas, no significant difference exists between nestin- and CD105-MVD, independently of the presence of tumor cells. Nevertheless, the existence of neoplastic elements in both the second and the third areas, seemed to increase CD105-MVD without influencing nestin-MVD. This strengthens the idea that CD105 expression is linked to tumor angiogenesis, while nestin is generally associated with endothelial activation.

A positive correlation for both nestin- and CD105-MVD between the second and the third areas was found. In addition, it is conceivable that in the third area endothelial activation testified by nestin-MVD may precede the acquisition of tumor characteristics by endothelium, revealed by CD105-MVD.

Notably, patients' survival was influenced by the values of the CD105-MVD in the third area, i.e., the tissue at a greater distance from the GBM border. In fact, patients with CD105-MVD values <8.0 compared with patients expressing higher MVD values showed a better median survival (15 vs 10 months). In addition, patients with CD105-MVD values $\geq 8.0$ had an about 3.5-fold higher risk of death.

Our findings revealed that the vascular characteristics of peritumor areas may have a prognostic value in addition to those of the neoplastic tissue. This is in complete agreement with our previous findings showing that JNK and nestin expression in the second area correlates with patients' survival (13).

Furthermore, these findings could lead to new therapeutic strategies not only directed at eradicating gross tumor but also at targeting invasive cells in apparently normal tissue, as well as de-differentiated elements and vascular structures that may support disease progression (35).

Anti-angiogenesis-based therapeutic approaches for glioma are underway in several clinical trials with controversial results $(36,37)$. Nevertheless, a CD105 nanobody-based treatment has recently proven to be effective in inhibiting endothelial cell proliferation and capillary-like structure formation offering high specificity towards tumors and reducing side effects (38).

While our particular sampling technique limited us to enroll all the patients operated on for GBM, this study provides unique information regarding peritumor tissue neoangiogenesis, with an appreciable number of observations concerning areas at various distances from the tumor margin. 


\section{Acknowledgements}

This study was supported by financial research contributions from the Catholic University of the Sacred Heart (G. Sica).

\section{References}

1. Kleihues P, Burger PC, Aldape KD, et al: Glioblastoma. In: WHO Classification of Tumors of the Central Nervous System. 4th edition. Louis DN, Ohgaki H, Wiestler OD and Cavenee WK (eds.) IARC, Lyon, pp33-46, 2007.

2. Rong Y, Durden DL, van Meir EG, et al: Pseudopalisading necrosis in glioblastoma: a familiar morphologic feature that links vascular pathology, hypoxia, and angiogenesis. J Neuropathol Exp Neurol 65: 529-539, 2006

3. Vajkoczy P and Menger MD: Vascular microenvironment in gliomas. J Neurooncol 50: 99-108, 2000

4. Vajkoczy P, Schilling L, Ulrich A, et al: Characterization of angiogenesis and microcirculation of high-grade glioma: an intravital multifluorescence microscopic approach in the athymic nude mouse. J Cereb Blood Flow Metab 18: 510-520, 1998.

5. Deane BR and Lantos PL: The vasculature of experimental brain tumors. Part 1. A sequential light and electron microscope study of angiogenesis. J Neurol Sci 49: 55-66, 1981.

6. Nowacki P and Kojder I: Peritumoral angiogenesis around primary and metastatic brain neoplasms. Morphometric analysis. Folia Neuropathol 39: 95-102, 2001

7. Bakshi A, Nag TC, Wadhwa S, et al: The expression of nitric oxide synthases in human brain tumours and peritumoral areas. J Neurol Sci 155: 196-203, 1998.

8. De Micheli E, Alfieri A, Pinna G, et al: Extracellular levels of taurine in tumoral, peritumoral and normal brain tissue in patients with malignant glioma: an intraoperative microdialysis study. Adv Exp Med Biol 483: 621-625, 2000.

9. Cubillos S, Obregón F, Vargas MF, et al: Taurine concentration in human gliomas and meningiomas: tumoral, peritumoral, and extratumoral tissue. Adv Exp Med Biol 583: 419-422, 2006.

10. Dehnhardt M, Zoriy MV, Khan Z, et al: Element distribution is altered in a zone surrounding human glioblastoma multiforme. J Trace Elem Med Biol 22: 17-23, 2008.

11. Stevenson CB, Ehtesham M, McMillan KM, et al: CXCR4 expression is elevated in glioblastoma multiforme and correlates with an increase in intensity and extent of peritumoral T2weighted magnetic resonance imaging signal abnormalities. Neurosurgery 63: 560-570, 2008

12. Lama G, Mangiola A, Anile C, et al: Activated ERK $1 / 2$ expression in glioblastoma multiforme and in peritumor tissue Int J Oncol 30: 1333-1342, 2007.

13. Mangiola A, Lama G, Giannitelli C, et al: Stem cell marker nestin and c-Jun NH2-terminal kinases in tumor and peritumor areas of glioblastoma multiforme: possible prognostic implications. Clin Cancer Res 13: 6970-6977, 2007.

14. Boutros T, Chevet E and Metrakos P: Mitogen-activated protein (MAP) kinase/MAP kinase phosphatase regulation: roles in cell growth, death and cancer. Pharmacol Rev 60: 261-310, 2008.

15. Hoefen RJ and Berk BC: The role of MAP kinases in endothelial activation. Vascul Pharmacol 38: 271-273, 2002.

16. Sugawara K, Kurihara H, Negishi M, et al: Nestin as a marker for proliferative endothelium in gliomas. Lab Invest 82: 345-351, 2002.

17. Dallas NA, Samuel S, Xia L, et al: Endoglin (CD105): a marker of tumor vasculature and potential target for therapy. Clin Cancer Res 14: 1931-1937, 2008.

18. Yao Y, Kubota T, Takeuchi H, et al: Prognostic significance of microvessel density determined by an anti-CD105/endoglin monoclonal antibody in astrocytic tumors: comparison with an anti-CD31 monoclonal antibody. Neuropathology 25: 201-206, 2005.
19. Kumar S, Ghellal A, Li C, et al: Breast carcinoma: vascular density determined using CD105 antibody correlates with tumor prognosis. Cancer Res 59: 856-861, 1999.

20. Tanaka F, Otake Y, Yanagihara K, et al: Evaluation of angiogenesis in non-small cell lung cancer: comparison between antiCD34 antibody and anti-CD105 antibody. Clin Cancer Res 7: 3410-3415, 2001.

21. Wikström P, Lissbrant IF, Stattin P, et al: Endoglin (CD105) is expressed on immature blood vessels and is a marker for survival in prostate cancer. Prostate 51: 268-275, 2002.

22. Dore-Duffy P: Pericytes: pluripotent cells of the blood brain barrier. Curr Pharm Des 14: 1581-1593, 2008.

23. Crisan M, Yap S, Casteilla L, Chen CW, Corselli M, Park TS, Andriolo G, Sun B, Zheng B, Zhang L, et al: A perivascular origin for mesenchymal stem cells in multiple human organs. Cell Stem Cell 3: 301-313, 2008.

24. Mangiola A, De Bonis P, Maira G, et al: Invasive tumor cells and prognosis in a selected population of patients with glioblastoma multiforme. Cancer 113: 841-846, 2008.

25. Stupp R, Mason WP, van den Bent MJ, Weller M, Fisher B, Taphoorn MJ, Belanger K, Brandes AA, Marosi C, Bogdahn U, et al: Radiotherapy plus concomitant and adjuvant temozolomide for glioblastoma. N Engl J Med 352: 987-996, 2005.

26. Hoelzinger DB, Mariani L, Weis J, et al: Gene expression profile of glioblastoma multiforme invasive phenotype points to new therapeutic targets. Neoplasia 7: 7-16, 2005.

27. Kleihues P, Burger PC, Collins VP, et al: Glioblastoma. In: Pathology and Genetics of Tumors of the Nervous System. Kleihues P and Cavenee WK (eds). IARC, Lyon, pp29-39, 2000.

28. Weidner N: Current pathologic methods for measuring intratumoral microvessel density within breast carcinoma and other solid tumors. Breast Cancer Res Treat 36: 169-180, 1995.

29. Vermeulen PB, Gasparini G, Fox SB, et al: Quantification of angiogenesis in solid human tumours: an international consensus on the methodology and criteria of evaluation. Eur J Cancer 32: 2474-2484, 1996.

30. Teranishi N, Naito Z, Ishiwata $\mathrm{T}$, et al: Identification of neovasculature using nestin in colorectal cancer. Int J Oncol 30: 593-603, 2007.

31. Vitolo D, Paradiso P, Uccini S, et al: Expression of adhesion molecules and extracellular matrix proteins in glioblastomas: relation to angiogenesis and spread. Histopathology 28: 521-528, 1996.

32. Feigin I, Allen LB, Lipkin L, et al: The endothelial hyperplasia of the cerebral blood vessels with brain tumors, and its sarcomatous transformation. Cancer 11: 264-277, 1958.

33. Morikawa S, Baluk P, Kaidoh T, et al: Abnormalities in pericytes on blood vessels and endothelial sprouts in tumors. Am J Pathol 160: 985-1000, 2002.

34. Dore-Duffy P, Katychev A, Wang X, et al: CNS microvascular pericytes exhibit multipotential stem cell activity. J Cereb Blood Flow Metab 26: 613-624, 2006.

35. Bello L, Giussani C, Carrabba G, et al. Angiogenesis and invasion in gliomas. Cancer Treat Res 117: 263-284, 2004.

36. Jain RK, Di Tomaso E, Duda DG, et al: Angiogenesis in brain tumors. Nat Rev Neurosci 8: 610-622, 2007.

37. Friedman HS, Prados MD, Wen PY, et al: Bevacizumab alone and in combination with irinotecan in recurrent glioblastoma. J Clin Oncol 27: 4733-4740, 2009.

38. Ahmadvand D, Rasaee MJ, Rahbarizadeh F, et al: Cell selection and characterization of a novel human endothelial cell specific nanobody. Mol Immunol 46: 1814-1823, 2009. 